د. منى أحمد قربان حجي محمد

\title{
وجهة نظر معلمات رياض الأطفال \\ حول تعليم اللغة العربية لأطفال الروضة بالكويث
}

\author{
دكتوره \\ منى أحمد قربان حجي محمد \\ ( مدرس في قسم المناهج وطرق التدريس ـ تخصص رياض أطفال ) \\ كلية التربية ـجامعة الكويث
}

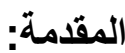

مرحلة الطفولة من أهم مراحل الحياة تأثيراً على نفسية الطفل حيث تتكون شخصيته التي تؤثر تأثنير اً كبير اً في مر احل حياته المستقبلية أما إيجاباً أو سلباً والروضة بما يتو افر فيها من مقومات تربوية تتمثل في المبني الملائم لخصائص وحاجات الأطفال و المعلمة المؤهلة تربوياً و علمياً ولديها ميل وحب للأطفال ودر اية وخبرة بكيفية التعامل معهم و المنهج المناسب لهذه المرحلة بما يحتويه من مفاهيم وحقائق وخبرات وأنشطة ملائمة لحاجات الأطفال وميولهم و المحققة لرغباتهم و المر اعية لاستعداداتهم والمرتبطة بييئتهم وفقاً لفلسفة المجتمع ومبادئه وقيمة وعاداته وثقافته. وتسعى رياض الأطفال لتحقيق الأهداف التربوية الثاملة بتهيئة بيئة غنية بالأنشطة و الوسائل الموزعة في أركان

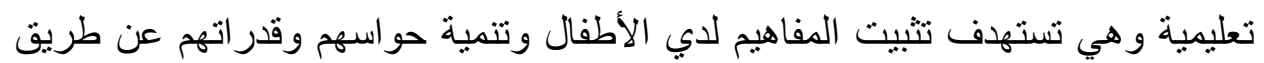
اللعب الحر والمحبب للأطفال و لأهمية اللغة العربية في إكساب أطفال الروضة في اكتساب مهارات اللغة من قراءة وكتابة جاءت هذه الدراسة لتتناول وجهة نظر معلمات رياض الأطفال حول تعليم اللغة العربية لأطفال الروضة بالكويت. مشكلة الدراسة: تعد مرحلة ما قبل المدرسة من المر احل المهمة في حياة الطفل إذ تتيح له الفرصة لاكتساب العديد من الخبرات الكافية لتنمية مهار اته و استعداداته للتعلم (ابر اهيم، م . . بم، 


\section{وجهة نظر معلمات رياض الأطفال حول تعليم اللفة العربية لأطفال الروضة بالكويت}

ص · (1) وفيها يمكن وضع الأساس للعملية التربوية عبر مراحل التعليم المختلفة

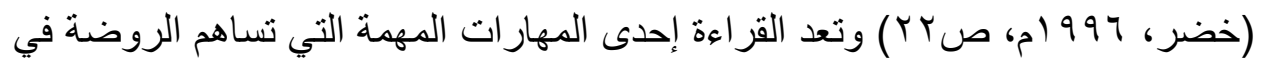

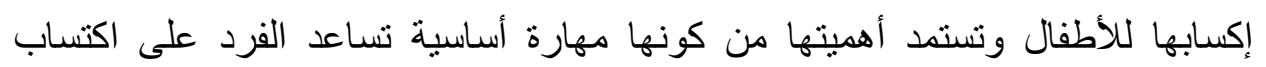

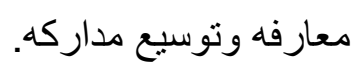

وتؤكد الكثير من الأبحاث على العلاقة الكبيرة بين القدرة الجيدة على القراعة وبين

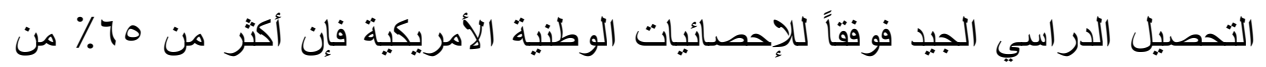
طلبة المدارس الثانوية المتسربين من التعليم هم الطلبة ذوي الأداء الضعيف في القراءة كما أظهرت دراسة ( Foulin, J. N. (2020) ) أن الطلبة منخفضي القدرة على

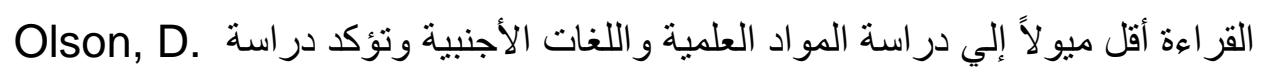
(R. أن الفنل في القراءة عند التلاميذ مرتبط بشكل كبير بمخالفة الأنظمة (2019) الدراسية وتزايد احتمالات الترسب من التعليم. كما اكدت بعض الدراسات التي تناولت مدي إتقان طلاب المرحلة الابتدائية في المملكة العربية السعودية لمهار ات القراءة وجد

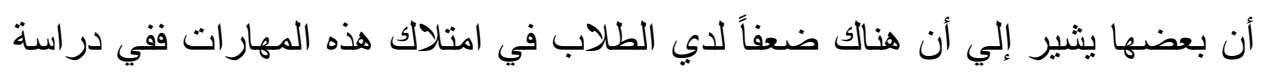
هدفت إلي قياس مدي إتقان طلاب الصف الثاني الابتدائي لمهارات القراءة بمدينة مكة إنة كانت نسبة الطلاب الذين بلغوا الحد المطلوب من الإتقان لمهارات مادة القراءة ضعيفة الابل

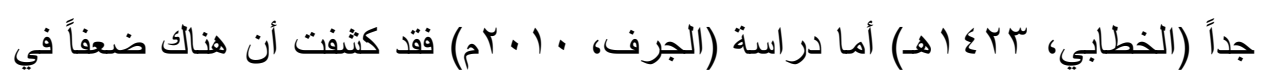
تحصيل مواد اللغة العربية ومن بينها القراءة لدي طلاب الصفوف العليا من المرحلة

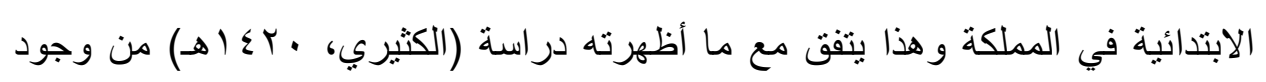

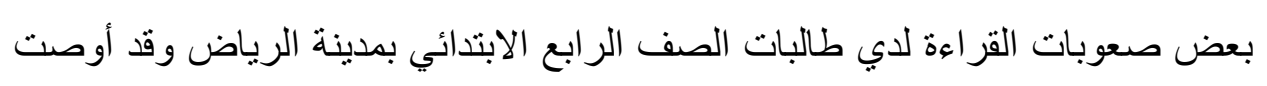

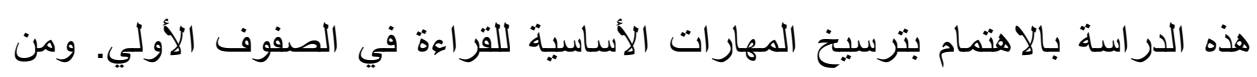
خلال ما أظهرته نتائج تلك الدراسات يبرز الدور الذي يمكن أن تقوم به مؤسسات

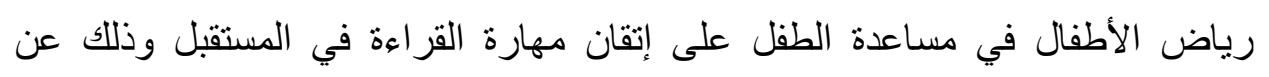
طريق إكسابه مهار ات الاستعداد للقراءة حتى يصل الطفل إلي مرحلة التعليم الأساسي 


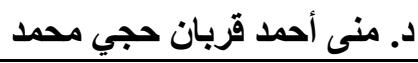

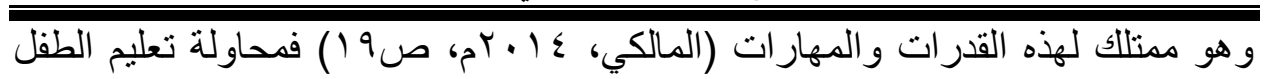
القر اءة قبل أن يكون مستعداً لها قد يؤدي إلي إطالة المدة المطلوبة للتعليم وإجهاد الطفل كما أنه قد يؤدي في بعض الأحيان إلي تكوين اتجاهات سلبية لدي الطفل نحو القراءة

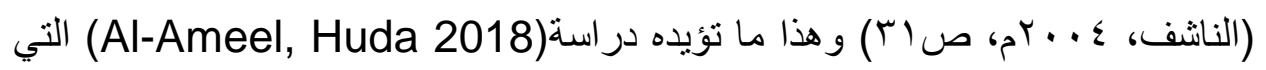
تؤكد أن الأطفال الذين يصلون إلي المدرسة الابتدائية وهم يفتقدون لمهار ات الاستعداد للقر اءة يكونون أكثر عرضة إلي التعثر في القراءة مستقبلاً. ( U.S Department of

.(Education, 1999, p2

كما أكدت العديد من الدراسات السابقة على أثر تعليم اللغة العربية على نمو

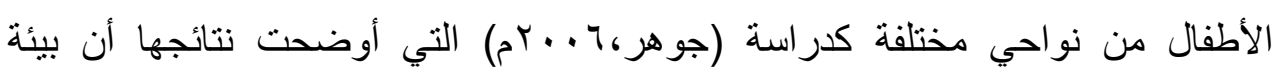
الأركان التعليمية كان لها أثر إيجابي واضح على النمو اللغوي والنمو الحركي لأطفال الروضة، ودراسة (الحسن، V. ...rم) التي أظهرت أن مستوى رسوم الأطفال ومسنوي تعبير هم اللغوي عن رسوماتهم ينطور بشكل أفضل في بيئة الأركان التعليمية عنه في

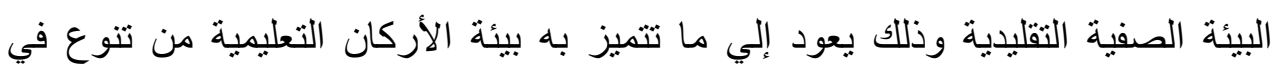
أساليب التعلم وتنوع في المو اقف والأنشطة وهذا ما يساهم في تحقيق النمو الثـامل للأطفال

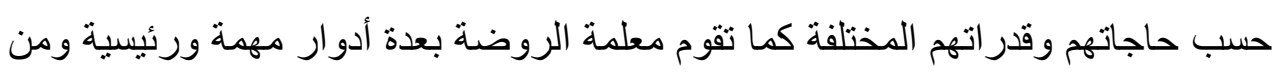
بينها دورها كداعمة لنمو وتعلم الأطفال وذلك من خلال ما تقدمه من أنشطة وخبرات

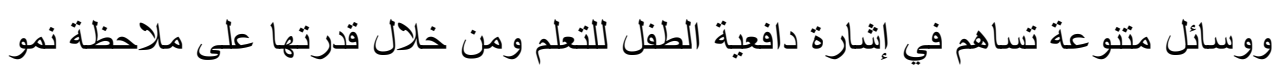
الطفل والاستفادة من هذه الملاحظة في التعرف على قدراته والعمل على تطويرها (الناشف، 997 (ام، صع VV). وتعتبر مرحلة رياض الأطفال مرحلة مهمة في إعداد الطفل لتعلم مهارة القراءة وذلك عن طريق إكساب الطفل مجموعة من المهارات نسمي

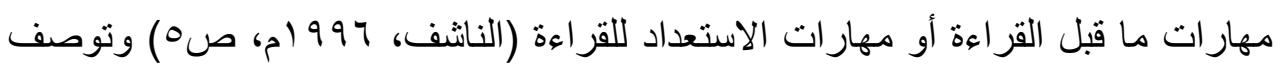

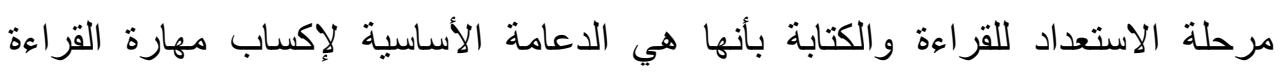
و الكتابة للطفل كما أنها مؤشر يدل على مستوى الطفل فيما بعد من حيث تقدمه أو تأخره 


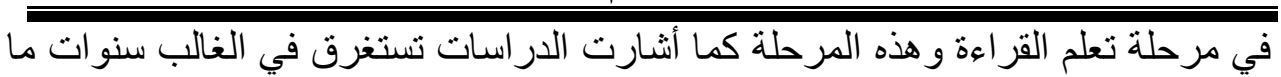
قبل المدرسة وقد تمتد لأكثر من ذلك بسنة أو سنتين حسب قدرة الطفل وذلك لأن القراءة شانها شأن أي مهارة أخري تحتاج إلي نضج عقلي وجسمي معينين كما أنها تحتاج إلي

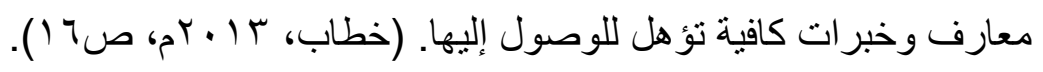
وبالنظر إلي طريقة تعليم القراءة والكتابة للأطفال من خلال منهج التعلم الذاتي المطبق في مؤسسات رياض الأطفال بدولة الكويت فقد أكد القائمون على إعداد هذا المنهج بأنه يهدف إلي بناء استعداد الطفل للقر اءة والكتابة ووضع الأرضية المتماسكة لها حتى يتمكن الطفل من الوصول إلي القر اءة والكتابة براحة ويسر حسب قدر اته الخاصة به. ونظر اً لأهمية تعليم اللغة العربية لأطفال الروضة كما أكدت على ذلك الدراسات السابقة جاءت هذه الدر اسة للتعرف على وجهة نظر معلمات رياض الأطفال حول تعليم اللغة العربية لأطفال الروضة بدولة الكويت.

\section{تساؤلات الدراسة وفرضياتها:}

ا ـهل توجد فروق ذات دلالة إحصائية لوجهة نظر معلمات رياض الأطفال نحو تعليم اللغة العربية لأطفال الروضة والتي تعزي إلي متغير المؤهل العلمي؟ Y-هل توجد فروق ذات دلالة إحصائية لوجهة نظر معلمات رياض نحو تعليم اللغة العربية لأطفال الروضة و التي تعزي إلي متغير الخبرة؟ r-هل توجد فروق ذات دلالة إحصائية لوجهة نظر معلمات رياض الأطفال نحو تعليم

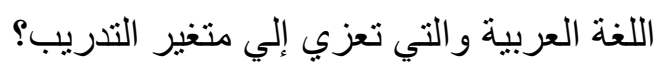
ـ ـ-هل توجد فروق ذات دلالة إحصائية لوجهة نظر معلمات رياض الأطفال نحو تعليم اللغة العربية والتي تعزي إلي متغير المنطقة التعليمية؟ 
ا -أن الاهتمام بمرحلة الطفولة يعد استثمارً أمثل لبناء مستقبل أي أمة وأن هذه المرحلة من المراحل المهمة في حياة الإنسان فقيها تتشكل أساسيات شخصية وتتحدد بشكل كبير ملامح نموه المستقبلية من جميع النواحي.

بr-تقديم توصيات ومقترحات للجهات التربوية المسئولية من رعاية وتربية الأطفال لكيفية تعليم اللغة العربية لأطفال الروضة لتحسين الجهات التربوية المسئولة من

$$
\text { رعاية وتربية الأطفال. }
$$

ـ -تقديم رؤية مستقبلية مقترحة يمكن أن يستقيد منها المسئولين في وزارة التعليم و أقسام رياض الأطفال واللغة العربية في الجامعات و إدارة التعليم والمؤسسات المجتمعية لتطوير رياض الأطفال بهدف تتمية المهارات اللغوية لأطفال الروضة.

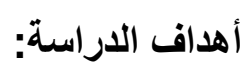

ا ـالتعرف على وجهة نظر معلمات رياض الأطفال نحو تعليم اللغة العربية لأطفال

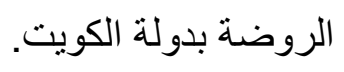

r-تقصي وجهات نظر معلمات رياض الأطفال دور كل من متغيرات (المؤهل العلمي -

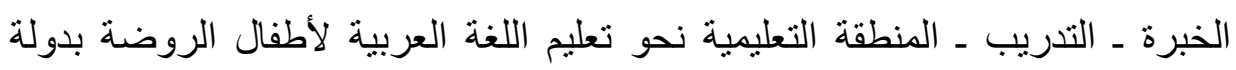

$$
\text { الكويت). }
$$

r-تحديد الفروق في وجهات نظر معلمات رياض الأطفال نحو تعليم اللغة العربية لأطفال الروضة طبقاً لمتغيرات (المؤهل العلمي ـ الخبرة ـ التدريب ـ المنطقة التعليمية). ـ ـاقتر اح رؤية مستقبلية لرياض الأطفال لتعليم اللغة العربية (القر اعة ـ الكتابة) لأطفال

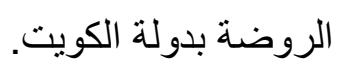




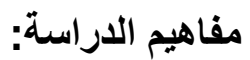

1-مرحلة رياض الأطفال:

هي مرحلة بالأطفال الصغار الذين أكملوا من عمرهم وهي تسبق المرحلة

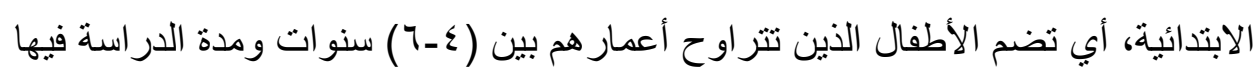

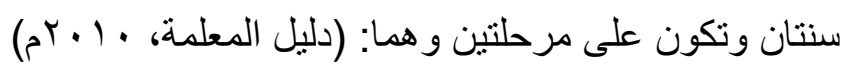

ويقصد بمرحلة رياض الأطفال في الدراسة الحالية على أنها مؤسسات تربوية تهتم برعاية وتعليم الأطفال من عمر الثالثة أو الرابعة حتى السادسة وتكسيهر مهارات تؤ هلهم للالتحاق بالتعليم الرسمي النظامي.

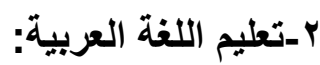

تتكون اللغة العربية في مرحلة رياض الأطفال عندما تتكون لديهم الاستعدادات الأولي لتعلم اللغة باكتسابهم الصورة يمكن من خلالها بناء منهج متكامل لتعليم اللغة

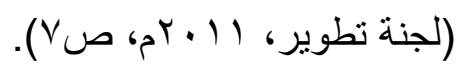

ويقصد بتعليم اللغة العربية جميع أنشطة الاستعداد اللغوي (القراءة ـ الكتابة ـ

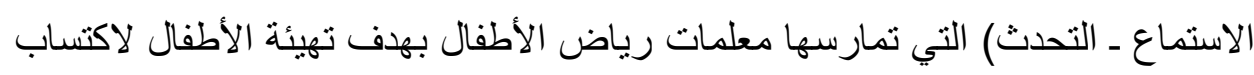
المهارات الأساسية اللازمة لتعلم اللغة العربية بكل بسر وسهولة عندما ينتقلون إلي المدرسة لاحقاً.

الإطار النظري للاراسة: للنمو اللغوي عند الطفل أهمية خاصة فهو يساعدنا على أن نفهم كيف ينمو كما أن قدرته على الكلام تدل على مدي نضجه الجسمي والسلوكي. ويتم

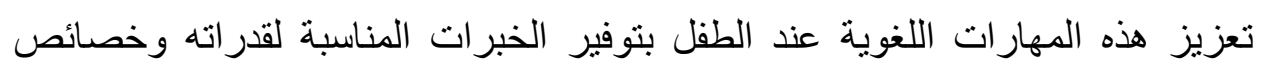
نموه ومناسبة للمرحلة العمرية للمتعلم في رياض الأطفال فمن الطرق المتبعة تعليم الأحرف الهجائية وأصوات الأحرف بالإضافة للأنشطة الكتابية والتي يقوم الطفل من 
د. منى أحمد قربان حجي محمد

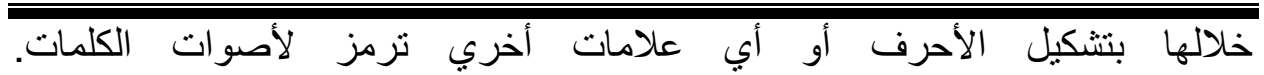

.(Aram,2006; Olson,2002)

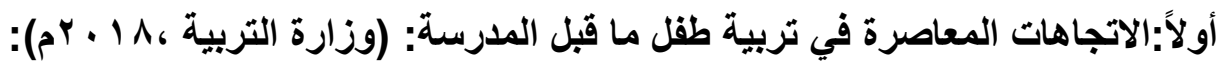
1 ـالتسليم بأهمية سنوات ما قبل المدرسة وخطورتها بالنسبة لنمو الأطفال في حاضرهم

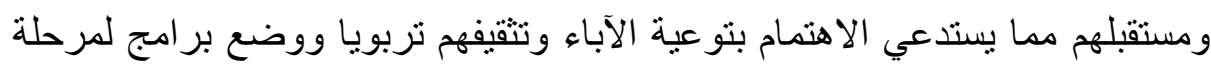

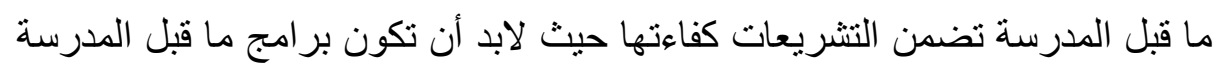
مناسبة لخصائص المجتمع وتطلعاته.

r-النظر إلي مرحلة ما قبل المدرسة على أنها جزء ضروري من تربية الطفل وأن رعاية النمو في هذه المرحلة ضروري للنجاح في التعليم في المراحل التالية وتأكيد قيام في هذا المجال بدور هم كمربين

r-تزايد تفهم الدور الذي يقوم به الآباء والمعلون كلما تزايد الاتصال بينهم ويمكن أن يكون عن طريق ما يلي: أ-مشاركة الآباء في إدارة المؤسسات التربوية. ب-الإفادة من المهارات الخاصة التي يمتلكها الآباء في البرامج التربوية. ج-تشجيع الآباء على زيارة المدارس و المشاركة في أنشطتها بالطرق المناسبة. ك-من الاتجاهات الحديثة في أساليب التعلم في الطفولة المبكرة توظيف اللعب لتتمية قدرات الطفل ومهار اته واتجاهاته أي توجيه اللعب فلا يكون حرا كل الوقت بل بل يعطي الطفل فرصة للعب الحر أحياناً لتحقيق أهداف تربوية محددة دون التخلي عن اللعب كأفضل أسلوب للأطفال في هذه المرحلة. 
وجهة نظر معلمات رياض الأطفال حول تعليم اللغة العربية لأطفال الروضة بالكويت

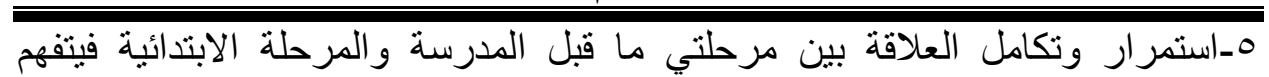
المعلمون في كل مرحلة الأدوار التي يقوم بها زملاؤهم في المرحلة الأخرى ويمكن تحقيق ذلك عن طريق ما يلي:

أ-تدريب معلمي المرحلتين في مؤسسة واحدة حتى يمكن لكل فريق الاطلاع على عمل الفريق الآخر والإلمام بحاجات الأطفال في أعمار مختلفة. ب-تجميع أطفال كل من المرحلتين في مؤسسة تربوية واحدة أو أن تكون مؤسسات كل من المرحلتين على صلة وثيقة ج-تنظيم البرامج التربوية للتدريب في أثناء الخدمة بحيث تناسب التربية كلا من المستويين.

د-صياغة الأهداف الخاصة بالتربية لكل مرحلة والإعلام بها. هـ-إنراك الأطفال في الأعمال المتصلة بالعالم الخارجي للمدرسة حيث أن كثيراً من الأعمال التي يقوم بها الأطفال لمساعدة الكبار لها قيمتها التربوية. و -الاستعانة بالآباء والأجداد وكل من يمكن الاستعانة به من الناس بطريقة مباشرة في

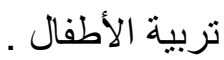

ا-الدور التعاوني للمنزل و المجتمع من أجل تحقيق نمو متكامل للطفل في سنوات ما قبل المدرسة و أهمية تثقيف الآباء.

V_التأكيد على الجوانب الإنسانية المشتركة في الثقافات الفرعية المختلفة بدلا من الاهتمام بما يميز ويفرق الجماعات الإنسانية حتى لا ينشأ الطفل في ظل أنماط ثقافية جامدة بل في إطار ثقافة واسعة مرنة مما يؤدي إلي الالتقاء في الفكر والأهداف بالنسبة لجميع شعوب العالم وتخفيف حدة الصر اعات الدولية. 


\section{د. منى أحمد قربان حجي محمد}

1ـ-تكوين اتجاهات إيجابية لازمة لهذا العصر عصر العلوم والتقدم التكنولوجي كتكوين اتجاهات ايجابية نحو العلم والعمل والتكنولوجيا في سن مبكرة لتقليل العزوف عن التعليم المهني و الفني وإعداد النشء المناسب .

ثانياً:فلسفة مرحلة رياض الأطفال في دولة الكويت: (وزارة التربية، ، ب · م) ا -فلسفة نابعة من قيم المجتمع الكويتي الذي يؤمن بالإسلام كدين فهي تعمل على: أ-تنمية القيم و الاتجاهات الدينية والخلقية لطفل الروضة. ب-أهمية توافق وتكامل الخبرات والبرامج والأنشطة المقدمة للطفل مع هذه القيم

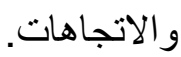

ץ-فلسفة عربية تتوافق وتتكامل مع واقع المجامع الكويتي ولذلك فهي تعمل على تتمية الاتجاهات نحو الكويت، والمجتمع الخليجي والأمة العربية والإسلامية.

ب-فلسفة تقوم على الإيمان بدور الأسرة الإيجابي والفعال في العملية التربوية ومن ثم فهي تعمل على توثيق الصلة بين الأسرة والروضة بهدف تحقيق نوع من التكامل لتربية الطفل وتنشئته بصورة نشمل كافة جوانب نموه النفسي و العقلي ع-فلسفة تؤكد روح الانتماء إلي الجماعة و تكوين علاقات وتفاعلات إيجابية مع الآخرين من الكبار ومن الأقران.

ه_فلسفة تحترم فردية الطفل وتفرده وتؤمن بكر امته وبحقه كإنسان وتتظر إليه كأمل أسرته . 7-فلسفة تؤمن وتعمل على تنمية الثقة بالنفس والمبادرة والاستقلال الذاتي وتكوين المفاهيم الإيجابية لدي الطفل. V-فلسفة تؤهن بأهمية حواس الطفل ومداركه عن طريق المثيرات الحسية والأنشطة المباثرة و الممارسة الفعلية. 
وجهة نظر معلمات رياض الأطفال حول تعليم اللفة العربية لأطفال الروضة بالكويت

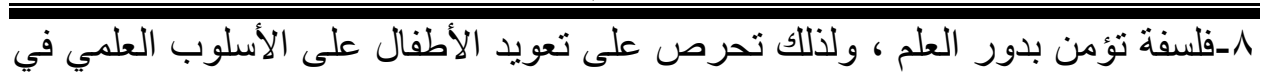
التفكير.

9-فلسفة تؤمن بدور المتعلم في المجمع المعاصر، ولذلك فهي تحرص على تحقيق نموه الثامل. • ـ ـفلسفة تنادي بتوظيف أساليب التربية القائمة على اللعب الحر و النشاط الذاتي التلقائي جنبا إلي جنب مع التربية المقصودة والموجهة لمساعدة الطفل على اكتساب المهارات مع تتمية الكفاءة العقلية و اللغوية للطفل بخاصة. | (-فلسفة تؤمن بضرورة ربط الأنشطاة والخبرات التي تقدم لطفل الرياض بواقع المجتمع وبالحياة وبالمستقبل المأمول.

إن تطوير المناهج والخطط التعليمية في مرحلة رياض الأطفال مطلب تربوي في غاية الأهمية يمثل استجابة حضارية لمتغير ات الحياة وتكيفا مع متطلبات الو اقع المتجددة ومو اكبة لنتائج البحوث و الدراسات التربوية ف مجال تعلم الطفل ومن هنا اتجه القائمون على التربية في دولة الكويت إلي تنفيذ مشروع إدخال تعليم اللغة العربية في مرحلة

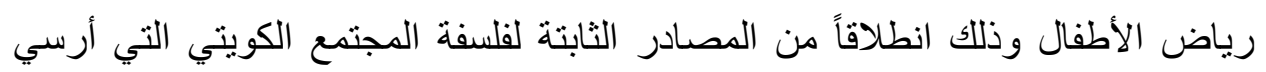
قو اعدها الدستور والتي استمدت وجودها من قيم الإسلام ومبادئه ومن طبيعة المتعلم ومراحل نموه ومطالب المرحلة التي تقوم على حاجات المجتمع الكويتي في حاضرة ومستقبله و انفتاحه الو اعي على طبيعة العصر من حيث خصائصهه ومقوماته ومتغير اته.

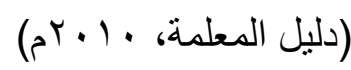

ويمكن التماس ملامح فلسفة تعليم اللغة العربية من أهمية اللغة للفرد والمجتمع ودور ها في حياة المتعلم في سياق مجتمعه وبيئته ووظيفته الاتصالية التي تربطه بتراث أمته وبمجالاته العلم و المعرفة على اختلاف أشكالها وتعدد اختصاصاتها وكونها عاملا أساسيا من عو امل تقدم المجمع ورقية. واللغة تبدأ مع الأطفال منذ صغر هم ويتطور 


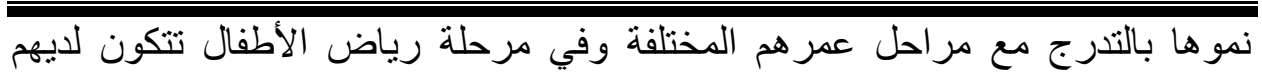
الاستعدادات الأولي لتعم اللغة واكتسابها بصورة يمكن من خلالها بناء منهج متكامل لتعليم اللغة، يقوم على المهارات الأولية البسيطة التي تمكنهم من الاتصـال اللغوي مع الآخرين و التفاعل مع بيئتهم وذللك يقوم على أن يتمتع الطفل بالقدرة على ما يأتي: ـالششاركة الفاعلة في كل موقف يمارس فيه نشاطا لغوياً بما يتوافر له من مهارات لغوية. ـاستخدام اللغة في بعض ألوان النشاط الأساسية اللازمة لحياته اليومية. -ممارسة هو ايات لغوية إبداعية يستطيع من خلالها تحقيق ذاته. -توسيع دائرة كفاياته وتنوع خبراته ومهار اته ونمو قدراته اللغوية بالإفادة مما تقدمه وسائل الإعلام المتنوعة . لمانع

ثالثاً: أسس وخصائص تعليم اللغة العربية بمرحلة رياض الأطفال:(وزارة التربية، $\left(a^{r} \cdot r \cdot\right.$ 1-الإلمام بطبيعة تعلم اللغة العربية وإدراك خصائصها: وتتمثل فيما يأتي: أ-أن اللغة بالمحاكاة والممارسة وأن التركيز في تعليمها يجب أن يكون على الممارسة اللغوية لا على الحديث عن اللغة نفسها بقو اعدها وقو انينها وضو ابطها. ب-أن اللغة العربية لغة معربة والضبط فيها عنصر جو هري من عناصر بنيتها ومن ثم فيجب ألا يفرط في هذا الضبط من بدء تعلمها ممارسة لا تعقيداً وتقنيناً ومن هنا تظهر معرئ أهمية حرص المعلمة على السلامة اللغوية مع أطفالها. ج-أن هناك قدراً مشتركاً بين اللغة الفصيحة و اللغة المحكية يمكن أن يستثمر في اكتساب المهار ات الأساسية للغة 


\section{وجهة نظر معلمات رياض الأطفال حول تعليم اللغة العربية لأطفال الروضة بالكويت}

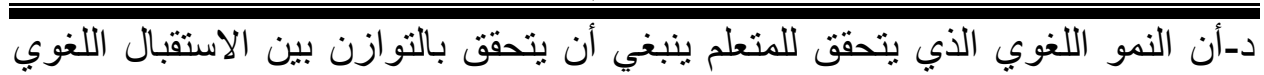
(الاستماع) و التعبير اللغوي (التحدث) وان مراعاة التكامل بين هذين الجانبين وما

$$
\text { يبادلانه من تأثير وتأثر أمر له أهميته. }
$$

هـ-أن للغة معاني مباشرة ومعاني مجازية والطفل يدرك في هذه المرحلة اللغة ذات

$$
\text { المعاني المباثرة و المفردات ذات الدلالة المحسوسة. }
$$

و-إن مراعاة المعلمة للتحدث باللغة الفصيحة بسهم إسهاماً كبيراً في اكتساب الطفل لمفردات اللغة ولمجمو عة من صيغها وتر اكيبها اللغوية عن طريق المحاكاة.

ز-أن اللغة تتصف بقابلية الإبداع ومن ثم على المعلمة مر اعاة قبول التغير ات المستحدثة من الأطفال التي تقدم معاني مفيدة وعدم تأطير تعلمهم بصيغ وتر اكيب لغوية ثابتة. ح-أن اللغة هي أداة التفكير وينبغي أن تكون تتمية تفكير المتعلم أمراً ملازماً لما يحدث له من نمو لغوي.

طـ-أن تكوين الميل عند المتعلم للغة وتحقيق حبة لها يساعده على تجاوز صعوبات اللغة ويسهم في امتلاك مهار اتها و المحتوي اللغوي وطر ائق تقديمه يؤديان دور اً مهماً في تحقيق هذه الغاية.

r-تعرف طبيعة المتعلم في هذه المرحلة العمرية وسماته النفسية: فالمتعلم يحتاج في هذه المرحلة إلي: أـالا هتمام ببناء شخصيته و احتر ام ذاته وقدر اته العقلية. ب_الاهتمام باجتماعيته بالإضافة إلي الاهتمام بذاتيته و أنه فرد في جماعة. ج-تعرف من حوله و استكثاف ما حوله و الخروج من محدودية البيت والأسرة إلي دوائر اجتماعية أوسع. 
هــالقدرة الطيبة و المثل الأعلى الذي ينسج على منو اله ويحاكيه في سلوكه و أدائه. و -تعرف قدراته و استعداداته وميوله وتوفير الرعاية اللازمة له في ضوء ذلك وخاصة عند الرغبة في التفوق والإبداع.

ز-تلبية حاجته إلي اللعب والنشاط و الحركة والميل إلي ترديد الأناشيد والاستماع إلي الآيات القر آنية والأحاديث الثريفة و الحكايات و القصص و الميل إلي الخيال و استنطاق

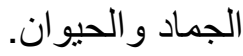

ح-تعرف قدرته على التعامل مع المحسوسات والمجردات وتبين مدي صعوبة استيعابه للمجردات و المعنويات ومر اعاة أن مدي الانتباه لديه في حدود ثناث دقائق.

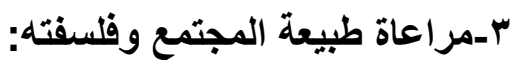

أ_أنه مجتمع عربي مسلم له عاداته وتقاليده ويعيش واقعاً له سماته وله تطلعاته

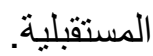

ب-و هو مجتمع منفتح على الثقافات المختلفة وتتسم حياته الاجتماعية بالتو اصل والتكافل وتربط بين أفر اده علاقات الأسرة الو احدة ويجمعهم الو لاء للوطن.

ج-أنه مجتمع حريص على ترسيخ قيمة الدينية وترسيخ قيمة الاجتماعية المقبولة من مثل التسامح واحتر ام الر أب و الآخر و العمل التطوعي و أداء الحقوق و إحسان العمل و إتقانه واحتر ام الكبير وتقدير العمل الثريف واحترام العاملين به وبخاصة الخدم والعمال و أصحاب المهن البسيطة. د-أنه مجتمع معني عناية كبيرة بفكرة بناء المستقبل والاستثمار البشري ومن ثم فهو حريص على تكوين اتجاهات إيجابية نحو اكتساب المعرفة وتقدر قيمة الوقت والتفكير المنظم و السليم وحل المشكلات . 
وجهة نظر معلمات رياض الأطفال حول تعليم اللفة العربية لأطفال الروضة بالكويت

منهجية الاراسة وإجراءواتها:

ا -منهج الدراسة: اتبعت الباحثة المنهج الوصفي الذي يدرس الواقع كما هو عليه بهدف التعرف على وجهة نظر معلمات رياض الأطفال نحو تعليم اللغة العربية لأطفال الروضة ومدي علاقته بمتغيرات الدراسة ، الخبرة، الدورات التدريبية، و المنطقة التعليمية، حيث يتم في هذا المنهج جمع البيانات وإجراء التحليل الإحصائي لاستخراج النتائج

r-مجتمع الدراسة: يتكون مجتمع الدراسة من مجموعة من معلمات رياض الأطفال في الكويت حيث بلغ مجموع العينة (197 ( ) معلمة ثم اختيار هن بطريقة مقصودة من (T) روضة موزعة على محافظات الكويث الست والتي تقوم بتجربة إدخال مواد لمنهج الطفل جميع المدرسات يضمن بالتدريس في فصول مختلفة وكل مدرسة لديها مساعدة في الفصل (غير مشاركة في البحث) تباينت مستويات المعلمات التعليمية، ثلاثة منهن تحمل شهادة الدبلوم من معهد المعلمات (، (1) يحملون شهادة البكالوريوس في التربية تخصص رياض أطفال و(r ا ) يحملون مؤهلات أعلى (الماجستير في التربية تخصص رياض الأطفال) وإجمالاً جميع المشاركات ( ... من العينة) تعليمهم السابق تركز على تخصص رياض الأطفال بالمتوسط سنوات الخبرة في التدريس كانت ( ـ0 سنوات. وفيما يلي توزيع أفراد العينة حسب المؤهل العلمي وسنوات الخبرة (جدول رقم ا ) جدول رقم ( ) بيان الخصائص لعينة الدراسة

\begin{tabular}{|c|c|c|c|c|c|c|}
\hline \multirow[t]{2}{*}{ الإجمالي } & \multicolumn{3}{|c|}{ المؤهل العلمي } & الاورة & \multirow[t]{2}{*}{ الخبرة } & \multirow[t]{2}{*}{ المنطقة } \\
\hline & عراسات & بكالوريوس & دبلوم & التدريبية & & \\
\hline $1 \varepsilon$ & & $1 \varepsilon$ & & & 0.1 & \multirow[t]{2}{*}{ العاصمة } \\
\hline iv & $r$ & $1 \varepsilon$ & & 1 & ج فأكثر & \\
\hline ir & & ir & & & 0.1 & حولي \\
\hline
\end{tabular}

العدد الخامس والاربعون (الجزء الثالى) T Y r.

(92)

مجلة كلية التربية- جامعة عين شثم 
د. منى أحمد قربان حجي محمد

\begin{tabular}{|c|c|c|c|c|c|c|}
\hline \multirow{2}{*}{ الإجمالي } & \multicolumn{3}{|c|}{ المؤهل العلمي } & الدورة & \multirow[t]{2}{*}{ الخبرة } & \multirow[t]{2}{*}{ المنطقة } \\
\hline & عليا & بكالوريوس & دبلوم & التدريبية & & \\
\hline 10 & 。 & 9 & 1 & r & ج فأكثر & \\
\hline iv & & iv & & & 0.1 & الفروانية \\
\hline iv & r & 10 & & $r$ & ج فأكثر & \\
\hline ir & & ir & & & 0.1 & الجهراء \\
\hline 11 & & 11 & & 1 & ج فأكثر & \\
\hline$r$ & & r & & & 0.1 & الأحمدي \\
\hline ro & 1 & $r \varepsilon$ & & $r$ & צ فأكثر & \\
\hline 10 & & 10 & & & 0.1 & مبارك الكبير \\
\hline 11 & $r$ & v & $r$ & 1 & ج فأكثر & \\
\hline 197 & ir & $1 \wedge$. & $r$ & 1. & & المجموع \\
\hline
\end{tabular}

rـأداة الاراسة: قامت الباحثة بإعداد إستبانة وكتابة بنودها في ضوء خبراتها وبالرجوع إلي الأدب التربوي والدراسات السابقة المتعلقة بوجهات النظر والآراء وتتكون هذه الإستبانة من مجالات المهارات اللغوية الحصيلة اللغوية، القراءة، الكتابة،

دور المعلمة في التواصل مع أسرة الطفل. ولقد اعتمدت الدراسة على الأدوات التالية: 1-المقابلات شبه المقننة والتي تم القيام بها أولاً مع بعض معلمات رياض الأطفال بالمنطقة التعليمية بالعاصمة والجهر اء للتعرف بصورة مبدئية على كيفية تعليم اللغة

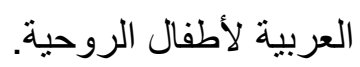

r-المقابلات الفردية و المشتركة: كأداة دراسية تربوية مع معلمات رياض الأطفال عينة

الدر اسة بالمنطقة التعليمية بالعاصمة و الجهر اء.

r-استبيان وجهة نظر معلمات رياض الأطفال (من إعداد الباحث) ويهدف هذا المقياس إلي قياس وتحديد مدي تعليم اللغة العربية لدي حالات الدراسة (المتغير التابع) 

ا-صدق المحتوي: قامت الباحثة بالتحقق من صدق المحتوي عول ديم من خلال: أ-مر اجعة وتحليل الأدبيات التي تناولت موضوع وجهة نظر معلمات الروضة نحو تعليم اللغة العربية لأطفال الروضة وكذلك مراجعة بعض الأدبيات والدراسات المرتبطة بالدر اسة.

ب-مر اعاة التنوع في اختيار بنود المقياس وأن يكون لكل بند هدف محدد وصياغة بنود المقياس على أن تكون واضحة ومفهومة وصياغة الإجابة على هذه البنود بأحد

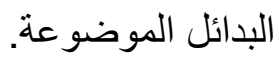

ج-صياغة تعليمات المقياس: تم صياغة تعليمات المقياس بعرض تعريف العينة على الهدف من الدراسة وتضمنت التعليمات التأكيد على البيانات الخاصة بمتغيرات الدراسة وكذلك طلب من أفراد العينة قراءة العبارات بدقة وعناية ومعرفة المقصود من كل عبارة و التأكيد على أنها بغرض خدمة البحث العلمي . د-التحقق من صدق القياس: جري التحقيق من صدق المقياس من خلال استخدام صدق المحتوي والصدق البنيوي بطريقة الاتساق الداخلي والصدق المحكي بدلالة محل المجموعات الطرفية وذلك من خلال تطبيق المقياس على عينة مؤلفة من (1/ ) من

$$
\text { معلمات الروضة. }
$$

Y_الصدق الظاهري: قام الباحث بعرض مقياس قلق المستقبل على عدد من المحكمين محكمين من المتخصصين في علم النفس و القياس و التقويم في كلية التربية جامعة الكويت وذللك للوقوف على سلامة البنود ومدي ارتباطها بالهدف العام للمقياس، وقدرتها على قياس الموضوع الذي أعدت لقياسه ومدي وضوح تعليمات حيث أبدي السادة المحكمون آرائهم في فقرات المقياس وبعد ذلك قام بإجر اء ما يلزم من تعديل و إضافة وحذف في ضوء مقترحاتهم. 
r-ثبات المقياس: قامت الباحثة بالتحقق من ثبات المقياس وذلك من خلال حساب معامل الارتباط بين درجات العبارات الفردية والعبارات الزوجية التي أسفر عنها نتائج التطبيق على العينة السابقة وقد بلغت قيمة معامل الثبات للمقياس ككل (r/, · ·) ولكل محور من

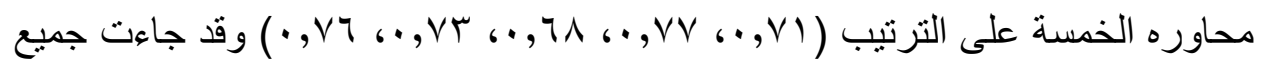
هذه القيم دالة إحصائياً عند مستوي معنوية ا.,, . مما يؤكد على تمتع المقياس بقدر مناسب من الثبات. حدود الاراسة: ا ـالحدود الزمانية: تتم إجراءات هذه الدراسة للفصل الدراسي الأول للعام الدراسي

$$
\text { . } r \cdot r \text {. }
$$

r-الحدود المكانية: تتحدد هذه الدراسة بالمنطقة التعليمية الآثية (العاصمة ـ حولي -

$$
\text { الفرو انية ـ الجهر اء ـ الأحمدي ـ مبارك الكبير). }
$$

بـالحدود البشرية: تقتصر الدراسة الحالية على معلمات رياض الأطفال بالروضات بالمناطق التعليمية.

نتائج الاراسة ومناقشتها:

السؤال الأول: هل توجد فروق ذات دلالة إحصائية بين معلمات رياض الأطفال نحو تعليم اللغة العربية لأطفال الروضة والتي تعزي إلي متغير المؤهل العلمي؟ وللإجابة عن هذا التساؤل قامت بحساب قيمة (F) وحساب الفروق في المتوسطات والانحر افات المعيارية بين معلمات رياض الأطفال نحو تعليم اللغة العربية

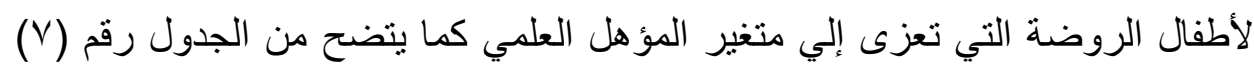

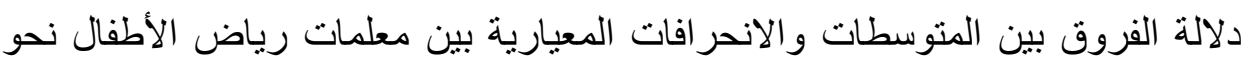
تعليم اللغة العربية لأطفال الروضة التي تعزي إلي متغير المؤهل العلمي. 
وجهة نظر معلمات رياض الأطفال حول تعليم اللفة العربية لأطفال الروضة بالكويت

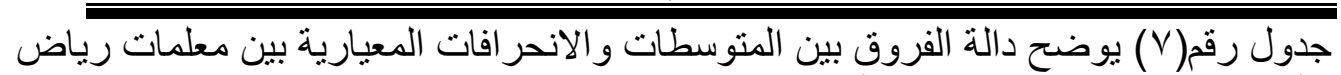

\begin{tabular}{|c|c|c|c|c|c|c|c|c|c|}
\hline \multirow{2}{*}{ مستوي } & \multirow[t]{2}{*}{ قيمة (F) } & \multicolumn{2}{|c|}{ دراسات عليا } & \multicolumn{2}{|c|}{ بكالوريوس } & \multicolumn{2}{|r|}{ دبلوم } & \multirow[t]{2}{*}{ المجال } & \multirow[t]{2}{*}{ P } \\
\hline & & انحراف & متوسط & انحراف & متوسط & انحراف & متوسط & & \\
\hline$\cdot, \cdot 1$ & $r, T V$ & 9,7 & $\varepsilon, v$ & Is & $\varepsilon, q$ & 1,04 & 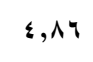 & |المهارات اللغوية & 1 \\
\hline$\cdot, .9$ & $1,7 v$ & 11,4 & $\varepsilon, \wedge$ & $1, \wedge v$ & $r, r$ & 11,4 & $\varepsilon, \wedge$ & | الحصيلة اللغوية & $r$ \\
\hline., .4 & 1,04 & ז & $\varepsilon, 0$ & $1, \vee \wedge$ & $\varepsilon, \wedge$ & 9,4 & $\varepsilon, \xi$ & | القراءة & $r$ \\
\hline,,.. & r,. O & $9, \wedge$ & $\varepsilon, 4$ & 1,04 & $\varepsilon, \xi$ & $9, \wedge$ & $\varepsilon, 4$ & | الكتابة & $\varepsilon$ \\
\hline.,$\cdot v$ & io & $q, r$ & $\varepsilon, \varepsilon$ & $\wedge 9$ & $\varepsilon, v$ & $a, r$ & $\varepsilon, \xi$ & 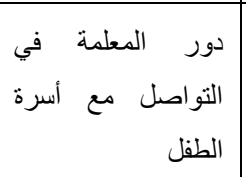 &. \\
\hline., .9 & $\Lambda, \vee$ & $1 ., 49$ & r, I. & ., rq & r,ir &., $\mathrm{rV}$ & $r, \cdot r$ & |الدرجة الكلية & \\
\hline
\end{tabular}

يتبين من الجدول رقم (V) عدم وجود فروق ذات دلالة إحصائية في متوسطات

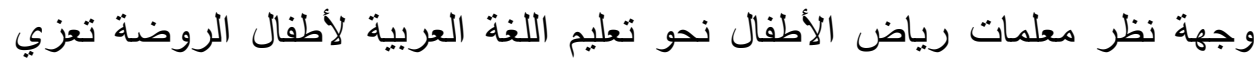
لمتغير المؤهل العلمي على الدرجة الكلية يوضح المقياس أن المقارنة بين متوسطات درجات مؤهل المعلمات دبلوم بكالوريوس دراسات عليا لا تختلف بشكل كبير فيما عدا بند الحصيلة اللغوية حيث بلغ المتوسط الحسابي مع المعلمات دبلوم (^, ؛) والمعلمات بكالوريوس (r,r) و المعلمات دراسات عليا (^, §) في حين وجد اتفاق في البنود التالية و هذا يعني أن الحاصلات على درجات علمية أخري تتثابه مع المعلمات الحاصلين على لى دبلوم أي أن أداء المعلمات لا يتأثر باختلاف المؤهلات التعليمية. السؤال الثاني: هل توجد فروق ذات دلالة إحصائية بين معلمات رياض الأطفال نحو تعليم اللغة العربية لأطفال الروضة تعزي إلي متغير الخبرة؟ 
د. منى أحمد قربان حجي محمد

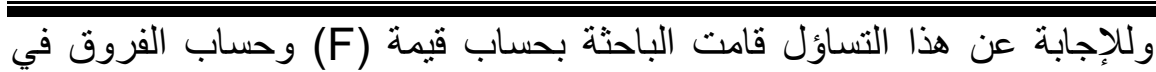
المتوسطات والانحر افات المعيارية بين معلمات رياض الأطفال نحو تعليم اللغة العربية لأطفال الروضة التي تعزي إلي متغير الخبرة كما يتضح من جدول رقم (^) دلالة الفروق بين المتوسطات والانحر افات المعيارية بين معلمات رياض الأطفال نحو تعليم اللغة العربية لأطفال الروضة التي تعزي إلي متغير الخبرة.

جدول (^) يوضح دلالة الفروق بين المتوسطات والانحر افات المعيارية التي تعزي إلي متغير الخبرة

\begin{tabular}{|c|c|c|c|c|c|c|c|c|c|}
\hline \multirow{2}{*}{ مستوي الالالة } & \multirow[t]{2}{*}{ قيمة (F) } & \multicolumn{2}{|c|}{ 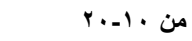 } & \multicolumn{2}{|c|}{ أقل من هـ . 1} & \multicolumn{2}{|c|}{ أقل من • سنوات } & \multirow[t]{2}{*}{ المجال } & \multirow[t]{2}{*}{ 5 } \\
\hline & & انحراف & متوسط & انحراف & متوسط & انحراف & متوسط & & \\
\hline., .0 & $1,1 \mathrm{r}$ & $r, v q$ & $\varepsilon, q$ & שד, & $\varepsilon, q$ & 1,1 & $\varepsilon, 9$ & المهارات اللغوية & 1 \\
\hline$\cdot, \cdot v$ & $1, v$ & $\cdot, \wedge \vee$ & $\leq, 1$ & . & $r, r$ & $1, v \vee$ & $\leq$ & الحصيلة اللغوية & r \\
\hline$\cdot, \cdot \wedge$ & $\cdot, \wedge \vee$ & 1,07 & $\varepsilon, \wedge$ & 1,07 & $\varepsilon, \wedge$ & . & $\leq, 9$ & القراءة & $r$ \\
\hline$\cdot, \cdot \varepsilon$ & (7, & $1, v v$ & $r, r$ & 1,07 & $\varepsilon, \wedge$ & 1,07 & $\leq, 9$ & الكتابة & $\varepsilon$ \\
\hline$\cdot, \cdot r$ & $\cdot, \mathrm{V} \bullet$ & r,TV & $r, v$ & $1, \vee v$ & $r, \tau$ &.,$\vee^{4}$ & $r, r$ & 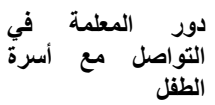 & 0 \\
\hline ., & $\bullet, 0$ & $r, .0$ & r,19 &.,$r$. & $r, \cdot r$ & $\cdot, r q$ & $r, I V$ & الدرجة الكلية & \\
\hline
\end{tabular}

يتبين من الجدول رقم (^) عدم وجود فروق ذات دلالة إحصائية في متوسطات اتجاهات معلمات رياض الأطفال نحو تعليم اللغة العربية لأطفال الروضة الذي يعزي إلي متغير الخبرة وعدم وجود فروق ذات دلالة إحصائية في درجة توافر إيجابية ترجع لمتغير سنوات الخبرة وبقيمة وزيادة التوضيح نجد أن درجة تو افر المهارات اللغوية لدي أفراد العينة كانت مرتفعة في حين نجد أن هناك اختلاف في بند الحصيلة اللغوية حيث

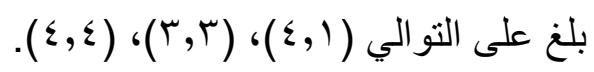

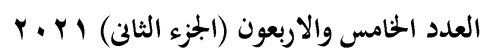

(97)

مجلة كلية التربية- جامعة عين شمس 
وجهة نظر معلمات رياض الأطفال حول تعليم اللغة العربية لأطفال الروضة بالكويت السؤال الثالث: هل توجد فروق ذات دلالة إحصائية بين معلمات رياض الاضلة الأطفال نحو تعليم اللغة العربية لأطفال الروضة تعزي إلي متغير التدريب؟ وللإجابة عن هذا التساؤل قامت الباحثة بحساب قيمة (F) وحساب الفروق في المتوسطات والانحر افات المعيارية بين معلمات رياض الأطفال نحو تعليم اللغة العربية لأطفال الروضة والني تعزي إلي متغير التدريب كما يتضح من جدول رقم (9) دلالة الفروق بين المتوسطات والانحر افات المعيارية بين معلمات رياض الأطفال نحو تعليم اللغة العربية لأطفال الروضة والتي تعزي إلي متغير التدريب.

جدول (9) يوضح دلالة الفروق بين المتوسطات والانحر افات المعيارية بين معلمات الئات

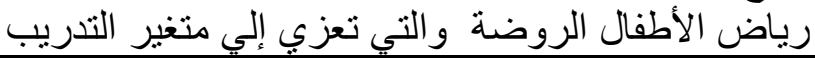

\begin{tabular}{|c|c|c|c|c|c|c|c|}
\hline \multirow{2}{*}{ مستوي } & \multirow{2}{*}{$\begin{array}{l}\text { قيمة } \\
\text { (F) }\end{array}$} & \multicolumn{2}{|c|}{ أكثر من واحدة } & \multicolumn{2}{|c|}{ دورة واحدة } & \multirow[t]{2}{*}{ المجال } & \multirow[t]{2}{*}{ م } \\
\hline & & انحراف & متوسط & انحراف & متوسط & & \\
\hline$\cdot, .0$ & $r, T V$ & $1, v \vee$ & $\leq, 7$ & $\cdot, \vee \wedge$ & $\leq, 9$ & المهارات اللغوية & 1 \\
\hline., .7 & I, & $\cdot, \vee \wedge$ & 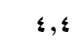 & 1,77 & $r, r$ & الحصيلة اللغوية & r \\
\hline.,.+1 & 1,07 & $\cdot, \wedge \vee$ & $\varepsilon, 0$ & 1,07 & $r, \xi$ & القراءة & $r$ \\
\hline.,.$\wedge$ & $\cdot, \wedge \vee$ & $1, \wedge \vee$ & $\varepsilon, r$ & $1, v \vee$ & $r, 1$ & الكتابة & $\varepsilon$ \\
\hline$\cdot, \cdot \wedge$ & 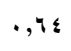 & $1, v \vee$ & $r, 0$ & 1,74 & $r, r$ & دور المعلمة في التواصل مع أسرة الطقل & $\bullet$ \\
\hline$\cdot, r_{0}$ & $r, . \wedge$ & r,l. & $r, . q$ &.,$r v$ & $v, \leqslant 4$ & الدرجة الكلية & \\
\hline
\end{tabular}

يتضح من جدول رقم (9) وجود الفروق بين المتوسطات و الانحر افات المعيارية بين معلمات رياض الأطفال نحو تعليم اللغة العربية لأطفال الروضة التي تعزي إلي متغير التدريب وأن المهارات اللغوية للمعلمات تختلف باختلاف عدد الدورات التدريبية التي التحقن بها ويتضح ذلك من الجدول رقم (9) و هذا يعني أنه يوجد فروق ذات دلالة إحصائية بين منوسطات درجات عينة الدراسة وفقاً لاختلاف عدد الدورات التي التحقن بها. 


\section{د. منى أحمد قربان حجي محمد}

السؤال الرابع: هل توجد فروق ذات دلالة إحصائية بين معلمات رياض إند الأطفال

نحو تعليم اللغة العربية والتي تعزي إلي متغير المنطقة التعليمية كما يتضح من جدول رقم (·1) دلالة الفروق بين المتوسطات والانحرافات المعيارية بين معلمات رياض الأطفال نحو تعليم اللغة العربية لأطفال الروضة والتي تعزي إلي متغير المنطقة

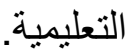

جدول ( • () يوضح دلالة الفروق بين المتوسطات والانحر افات المعيارية بين معلمات رياض الأطفال نحو تعليم اللغة العربية لأطفال الروضة والتي تعزي إلي متغير المنطقة التعليمية

\begin{tabular}{|c|c|c|c|c|c|c|c|}
\hline \multirow{2}{*}{ الدلالة } & \multirow[t]{2}{*}{ 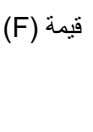 } & \multicolumn{2}{|c|}{ منطقة التعليمية (ب) } & \multicolumn{2}{|c|}{ منطقة التعليمية (أ) } & \multirow[t]{2}{*}{ 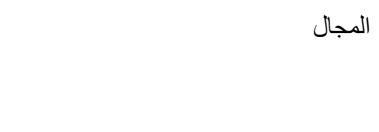 } & \multirow[t]{2}{*}{ s } \\
\hline & & انحراف & متوسط & انحراف & متوسط & & \\
\hline$r, \wedge$ & $\cdot, \cdot r$ & $1, v v$ & $r, 0$ & $\cdot, \mathrm{V} \vee$ & $\leq, 9$ & المهارات اللغوية & 1 \\
\hline$r, V Y$ & $\cdot, \cdot v$ & 1,09 & $r, q$ & $1, v V$ & \&, & الحصيلة اللغوية & $r$ \\
\hline 1,9 & $\cdot, \cdot \Lambda$ & V & $r, 0$ & $\cdot, \mathrm{\vee} \wedge$ & $\varepsilon, q$ & القراءة & $r$ \\
\hline., .1 &.,$\wedge \vee$ &., $\mathrm{\wedge}$ & $r, 0$ & 1,09 & $\leq, 1$ & الكتابة & $\leq$ \\
\hline$\cdot, \cdot \wedge$ & . $7 \leqslant$ & $1, \wedge \vee$ & r, $q$ &., 04 & $r, v$ & دور المعلمة في التواصل مع أسرة الطقل & 0 \\
\hline$\cdot, \cdot \wedge$ & $r, . r$ & $\cdot, 01$ & $\cdot, r q$ & $r, 10$ & $\cdot, r \wedge$ & الدرجة الكلية & \\
\hline
\end{tabular}

يتضح من جدول رقم ( • ( ) دلالة الفروق بين المتوسطات و الانحر افات المعيارية بين معلمات رياض الأطفال نحو تعليم اللغة العربية لأطفال الروضة والتي تعزي إلي متغير المنطقة التعليمية يرجع هذا الاختلاف في تكوين المهار ات اللغوية إلي مدي تو افر الإمكانات المادية إلي طبيعة الحياة الاجتماعية و الثقافية للمعلمة و الطفل والأسرة.

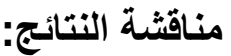

1- أشنارت النتائج إلي أن درجة المهارات اللغوية مرتفعة نحو تعليم اللغة العربية لأطفال الروضة بشكل عام وتعتبر معلمة الروضة عاملاً حاسماً في العملية التعليمية 
وجهة نظر معلمات رياض الأطفال حول تعليم اللغة العربية لأطفال الروضة بالكويت

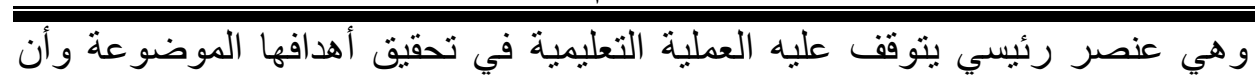
المهارات اللغوية تقرر مدي نجاحها في حياتها على المستوي الثخصي والمهني فإذا كان لدينا مهار ات لغوية نحو عملنا فإن هذا سيدفعنا إلي محاولة التخطي و التغلب على كل المعوقات الإحباطات التي تواجهنا وتعوق نجاحنا في العمل وتتفق هذه النتائج مع

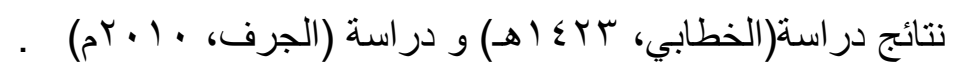
r- تعثقد الباحثة أن المهارات اللغوية الكبيرة للمعلمات نحو تعليم اللغة العربية لأطفال الروضة والتي أظهرتها النتائج كفيلة بأن تتبني وزارة التربية سياسة تطبيقية حازمة في تتفيذ المعلمات لهذا المنهج مع ضرورة توفير التوجيه والإشراف الجيد فقد أظهرت بهري

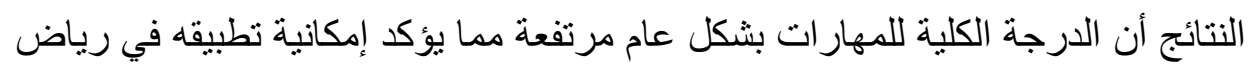
الأطفال والاهتمام به من خلال زيادة المعرفة النظرية أو إتباع الدورات التدريبية

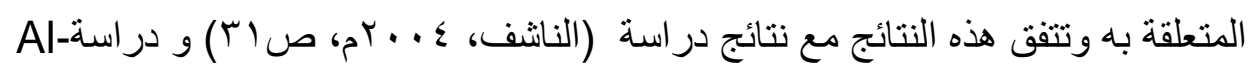

(Ameel, Huda 2018)

r- أصبح دور المعلمة في تعليم اللغة العربية أكثر فعالية وإيجابية فأصبح لها دور في وضع المنهج والأنشطة المختلفة التي تنتاسب مع احتياجات الأطفال وكذلك بناء على لمؤشرات والمعايير القومية لرياض الأطفال ووضع مؤشرات مربع التكامل وكذلك دور ها في وضع الخطط السنوية والثهرية والأسبو عية وعمل ملفات الإنجاز للأطفال

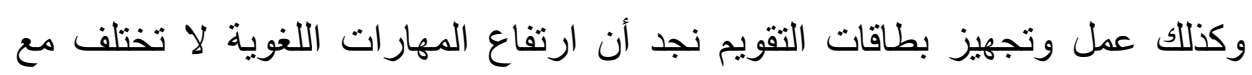

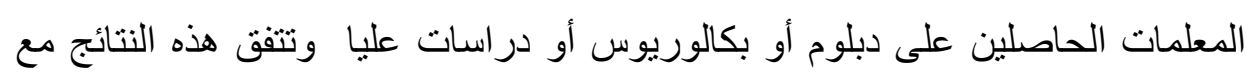

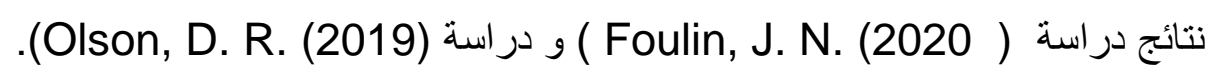
ع- - تبين أن وجهة نظر المعلمات نحو تعليم اللغة العربية لأطفال الروضة إيجابية وقد يعود السبب في ذلك إلي طبيعة تعليم اللغة العربية حيث يساعد المعلمة في مراعاة الفروف الفردية بين الأطفال وإيصال المعلومات للأطفال و إثارة الدافعية لديهم بما لهابه يحتويه من أنشطة مقترحة عن طريق بنك الأنشطة وهو مرفق ضمن القراهة والكتابة

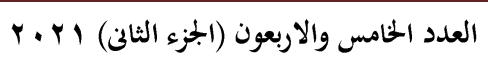

$$
\begin{aligned}
& \text { (100) } \\
& \text { مجلة كلية التربية- جامعة عين شمس }
\end{aligned}
$$


د. منى أحمد قربان حجي محمد

بالإضافة إلي رغبة المعلمات في مسايرة التطور العلمي والتكنولوجي و اتفقت هذه دهي

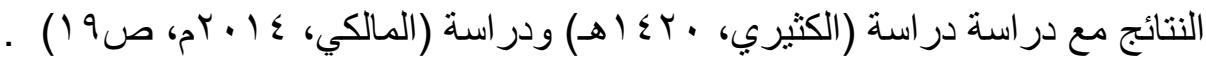
0- تسهم الاتجاهات الإيجابية نحو تعليم اللغة العربية في الارتقاء بمستوى العملية التعليمية ذاتها من خلال ما توفره للمعلمة من دافعية وحب لمهنتها تتعكس على أداء المعلمة وفعاليتها داخل قاعة النشاط، وعلى الأنشطة والمهام التي تقدمها للأطفال وتسعي لإكسابهم تلك الأنشطة والمهام و هذا ينعكس على أداء الأطفال ويزيد من فعاليتهر في الأنشطة عندها يكون المناخ السائد هو مناخ الإبداع والتعلم الذاتي والحرية وهذا ما

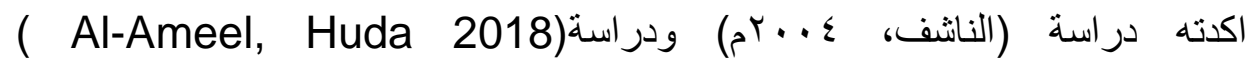

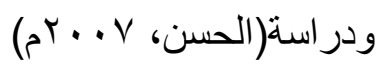

روئة مستقبلية مقترحة لرياض الأطفال لتعليم اللغة العربية (القراءة أو الكتابة) لأطفال الروضة: أولاً: متطلبات تعليم المهارات اللغوية (القراعة أو الكتابة) لأطفال الروضة:

\begin{tabular}{|c|c|c|}
\hline خطو ات مساعدة & في أرجاء الصف/ الأركان & خلال اللقاء الصباحي \\
\hline الوحة التخطيط مع الطفل عنونة أعمال & 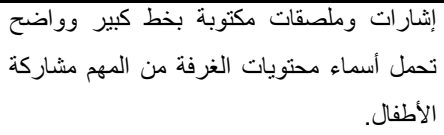 & 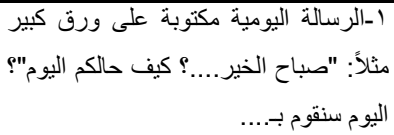 \\
\hline قراءة القصص للأطفال وتشجيعهم على & ودليل التلفاز و وبيره. & 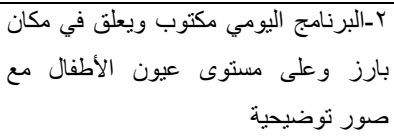 \\
\hline الأطفابة قصة يرويها الطفل أو مجموعة من & والعناب و أنشطة مرتبطة بالأحرف و والكلمات & 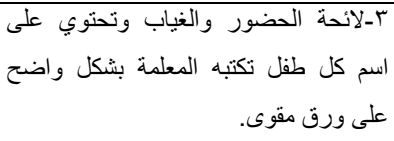 \\
\hline
\end{tabular}




\section{ثانياً: نموذج للمهارات اللفوية (القراءة أو الكتابة) لأطفال الروضة:}

\begin{tabular}{|c|c|}
\hline & \\
\hline 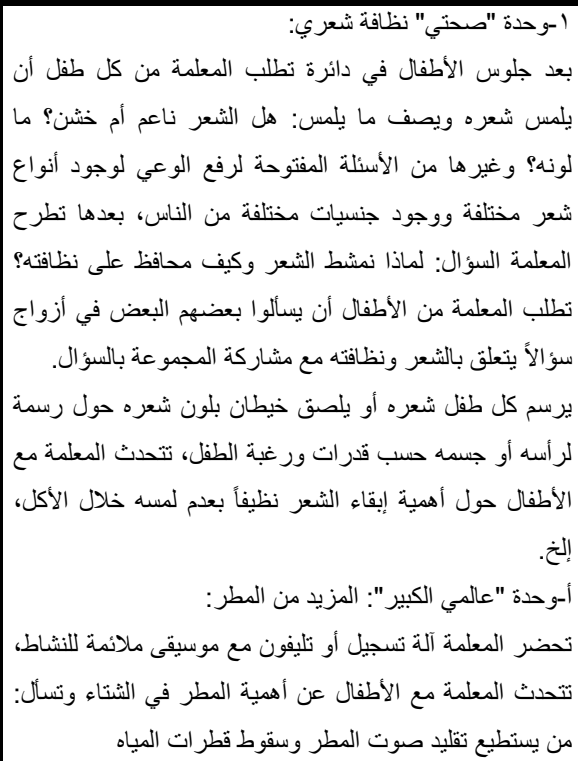 & 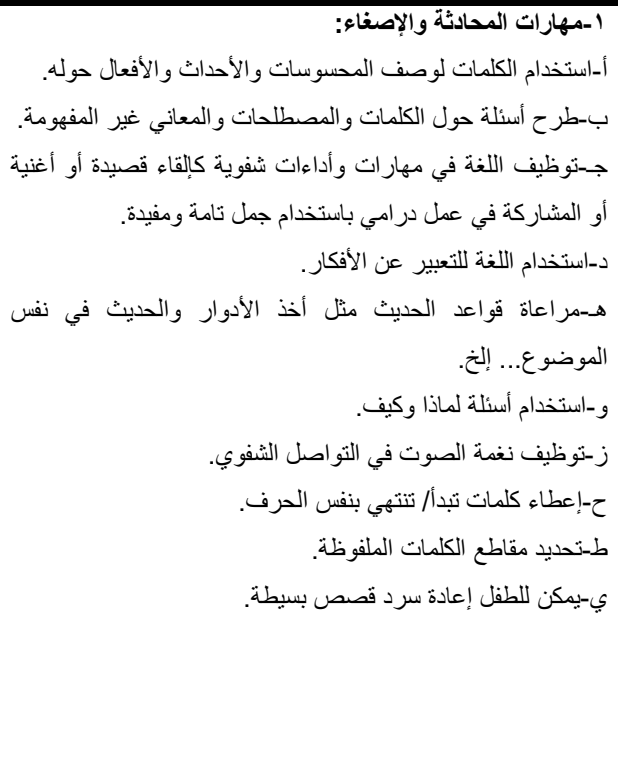 \\
\hline 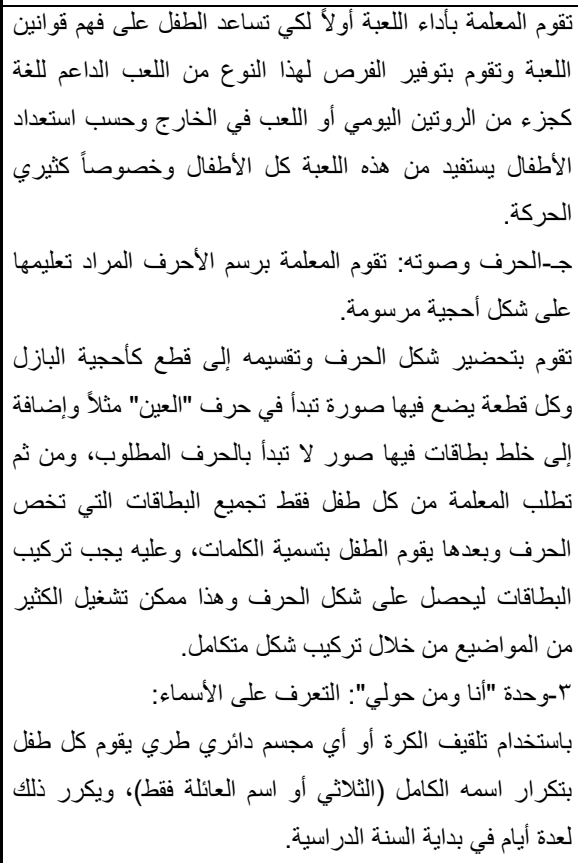 & 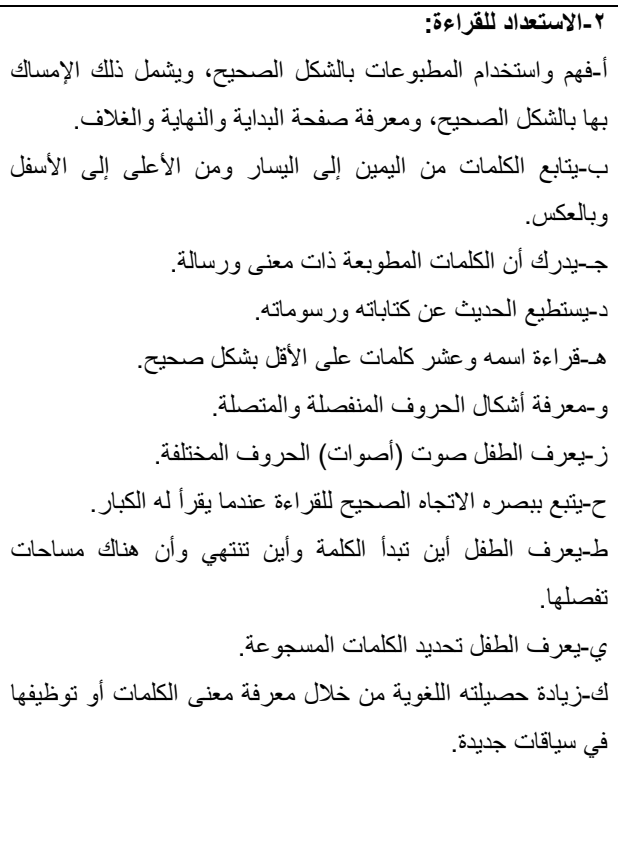 \\
\hline
\end{tabular}

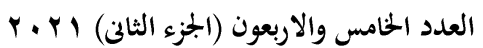

(102)

مجلة كلية التربية- جامعة عين شثم 
د. منى أحمد قربان حجي محمد

\begin{tabular}{|c|c|}
\hline 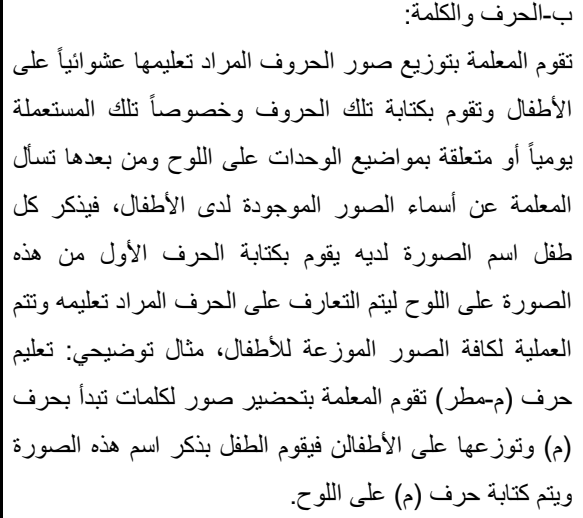 & 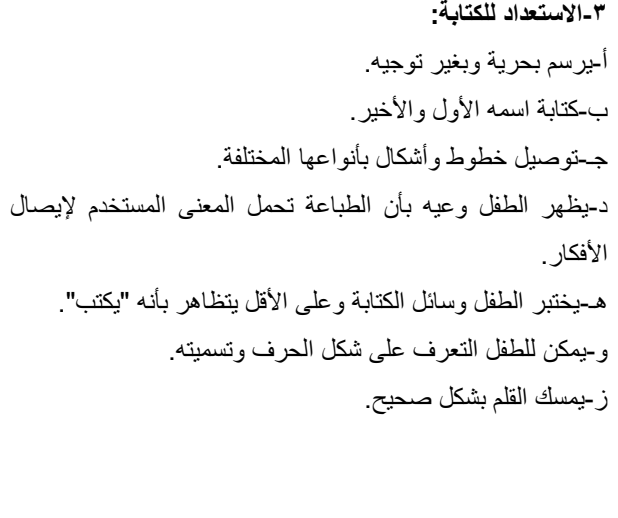 \\
\hline
\end{tabular}

التوصبات:

ا -ضرورة عقد دور ات تدريبية مكثفة لمعلمات رياض الأطفال على طريقة تدريس اللغة

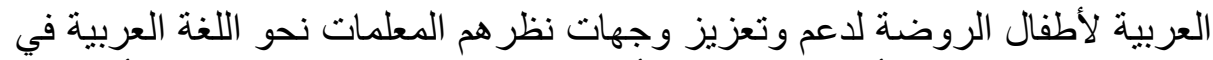

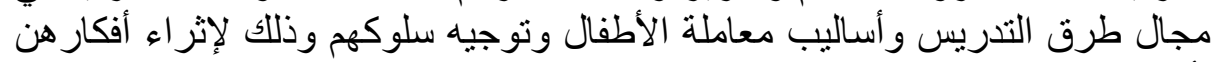
بأمثلة وتدريبات وتطبيقات تربوية بسيطة.

Y-يتوجب على كليات رياض الأطفال أن تكون وثيقة الصلة بالمجتمع وأن تحافظ على

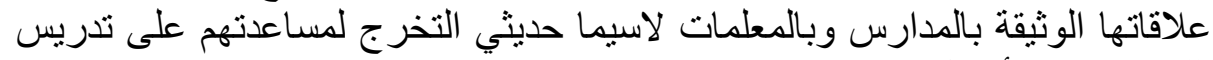

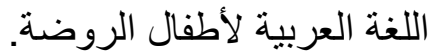

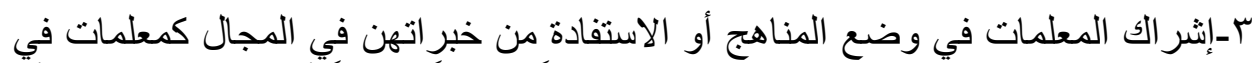

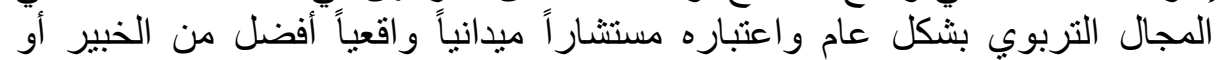
المنظر المثالي.

ع-ضرورة تطوير أساليب متابعة وتقويم المعلمات في ضوء الأهداف المرسومة لها

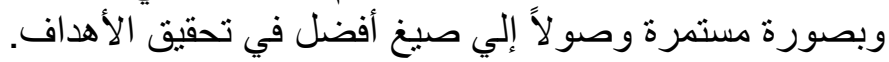

ه-ضرورة أن تعقد الندوات والمحاضر ات السنوية والفصلية والأسبوعية دورياً وذلك محالك لإطلاعهم على ما يستجد في مجال التدريس ومجال تخصصاتهم في مجال اللغة العربية.

7-استمرار القيام بالبحوث للوصول لأفضل الأساليب الواقعية التي تصلح لعملية

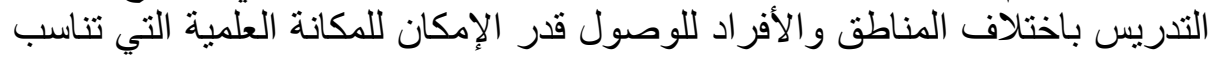
المجتمع. 


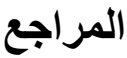

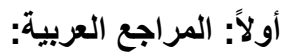

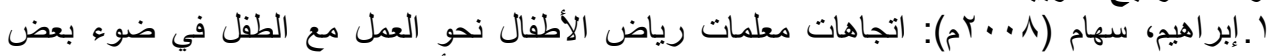

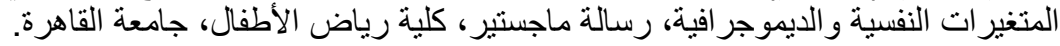

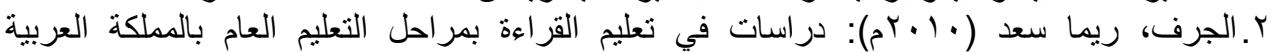

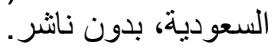

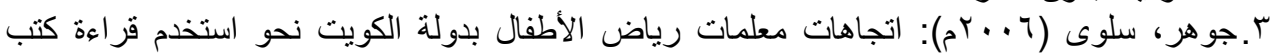

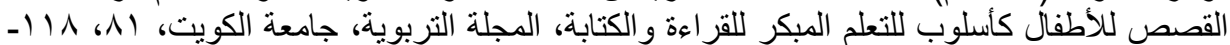
.119

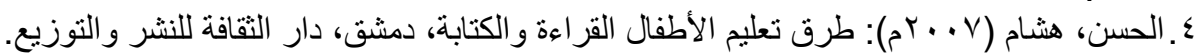

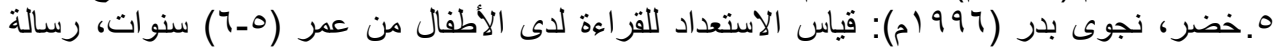

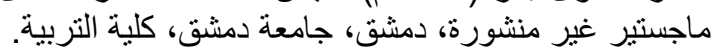

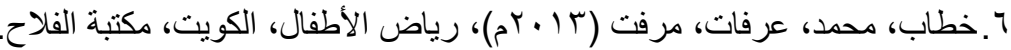

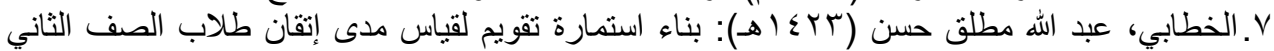

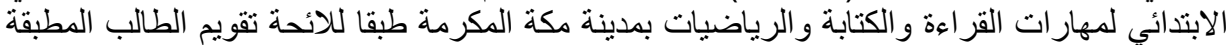

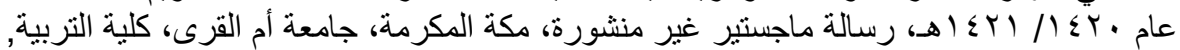

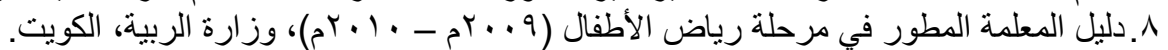

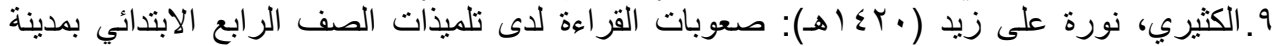

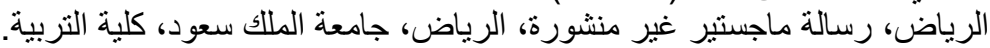

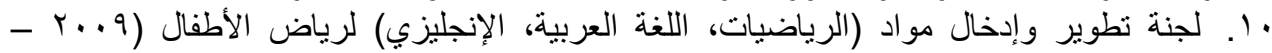

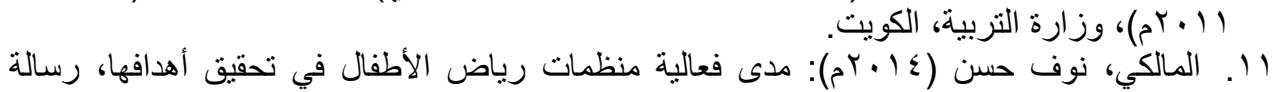

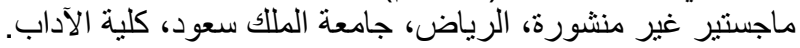

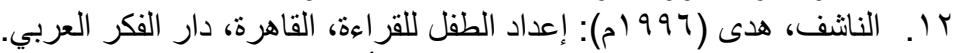

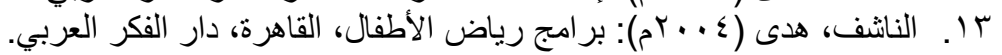

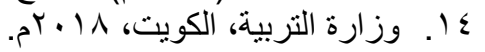

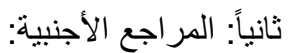

1- Al-Ameel, Huda (2018): the effect of different types of preschool curriculum on some aspects of children's experience and development in Saudi Arabia, Doctoral degree dissertation, Cardiff university, England.

2- Aram, D. (2006): Early literacy interventions: The relative roles of storybook reading, alphabetic activities, and their combination, Reading and Writing, 19.

3-Olson, D. R. (2019): what writing does to the mind. In E. Amsel \& J. P. byrned (Eds.), Language, Literacy, and cognitive Development and consequences of symbolic communication .

4- Schatschneider et al (2014): "kindergarten prediction of reading skills: A Longitudinal comparative analysis", Journal of educational. U.S Department of Education, 96 (2),

5- U.S Department of Education (1999): Start early finish strong -How to help every child become a reader .

العدد الخامس والاربعون (الجزء الثانى) Y r. ا

(104)
مجلة كلية التربية- جامعة عين شمس 